\title{
EFEKTIVITAS KONSELING BERBASIS MEDIA SOSIAL TERHADAP PERILAKU HIDUP BERSIH DAN SEHAT
}

\author{
Mulyanti' ${ }^{1}$ Imas Masdinarsyah ${ }^{2}$ \\ ${ }^{1,2)}$ Universitas 'Aisyiyah Bandung \\ yanti120511@gmail.com
}

\begin{abstract}
ABSTRAK
Berdasarkan hasil analisis Alat Ungkap Masalah (AUM) saat studi pendahuluan, aspek masalah tertinggi ada di bidang kesehatan dan pekerjaan sejumlah 50\% dan kecemasan di masa pandemi. Keberhasilan promosi kesehatan penanggulangan COVID-19 saat ini memerlukan peningkatan kepedulian antar keluarga/tetangga dalam menerapkan PHBS (Perilaku Hidup Bersih dan Sehat) agar tercipta lingkungan bebas COVID-19. Masyarakat memerlukan konseling akan masalahnya. Namun, sebagian besar menyatakan lebih memilih cukup bercerita tentang permasalahannya baik ke media sosial maupun teman dekat. Pelaksanaan konseling telah mengalami perubahan berarti yang dipengaruhi oleh perkembangan teknologi informasi, konseling secara konvensional telah berubah dan merambah dunia maya serta media sosial untuk memudahkan proses konseling PHBS yang merupakan masalah global masyarakat dunia. Penelitian ini untuk mengetahui efektivitas konseling berbasis media sosial terhadap PHBS masyarakat serta meningkatkan perilaku pro-PHBS pada masyarakat. Metode penelitian kuantitatif menggunakan pendekatan analitik dengan rancangan penelitian quasy experiment desain pre-test post-test satu kelompok. Sampel diambil dengan memberikan jatah atau quorum tertentu terhadap kelompok/sampling kuota dengan rumus Slovin didapatkan sejumlah 40 orang tanpa kelompok kontrol. Pada kelompok eksperimen dilihat pre-test sebelum perlakuan dan post-test setelah adanya perlakuan. Uji Wilcoxon menunjukkan $p$-value 0,000 sehingga dapat disimpulkan bahwa ada efektivitas yang berpengaruh dari konseling melalui media sosial WhatsApp terhadap perubahan pengetahuan, sikap, dan PHBS yang meningkat pada masyarakat. Peneliti berikutnya dapat menambahkan variabel perilaku serta kelompok pembanding.
\end{abstract}

Kata kunci: konseling, media sosial, pengetahuan, PHBS

\begin{abstract}
According to the analysis of Alat Ungkap Masalah (AUM) during the preliminary study, the highest problem aspects were in the health and work field at 50\% and anxiety during the pandemic. At this time, the success of health promotion for COVID-19 countermeasure requires increased awareness among families or neighbors in implementing (Perilaku Hidup Bersih dan Sehat) PHBS (Clean and Healthy Lifestyle Behavior (CHLB) in order to create a COVID-19 free environment. The societies need counseling on their problems. However, most of them said that it was most enough to just tell their problems to social media and friends. The implementation of counseling has undergone significant changes which are influenced by the development of information technology. The conventional counseling has changed and penetrated the virtual world and social media. This study was conducted to determine the effectiveness of social media-based counseling on PHBS in the societies. The quantitative research method used an analytical approach with a quasy experimental research design with a one group pre-test and post-test design. The sampling in this study was 40 people without a control group, where the experimental
\end{abstract}


group was conducted a pre-test before treatment and post-test after treatment. Based on the results of the Wilcoxon Test, it was obtained that the p-value was 0.000. It can be concluded that there is an influential effectiveness of counseling through WhatsApp social media on increasing knowledge, attitudes and behavior of PHBS in the society. Further researchers are expected to increase this study by adding behavioral variables and comparison groups.

Keywords: counseling, knowledge, PHBS, social media

\section{PENDAHULUAN}

Saat ini di kehidupan masyarakat banyak mengalami perubahan. Salah satunya perubahan paradigma cara manusia berinteraksi dengan manusia lainnya. Cara berkomunikasi masyarakat lebih banyak menggunakan metode tidak langsung dengan alat/media yang jenisnya beragam beralih ke alat yang canggih. Berbagai kecanggihan saat ini salah satunya lewat internet. Adanya media/alat yang canggih dalam berkomunikasi misalnya dengan media sosial yang membuat jarak, waktu dan ruang tidak lagi menjadi masalah dan mempermudah masyarakat dalam menjangkau dan berkomunikasi dengan keluarga, sahabat serta rekan kerja. Menurut data sebuah survei, saat ini ada 88 juta masyarakat Indonesia yang menggunakan media sosial (Ifdil, 2013).

Pada pelaksanaanya konseling mengalami perubahan yang bermakna saat ini. Kemajuan ilmu teknologi dan informasi banyak memberikan pengaruh terhadap perubahan tersebut. Saat ini perkembangan yang berkaitan dengan kecanggihan dunia komputer telah mencapai tahap puncak (sophisticated) sehingga hal tersebut dapat digunakan oleh sebagian besar penduduk Indonesia. Bahkan saat ini masyarakat kita dapat disimpulkan berada pada pengaruh kecanggihan teknologi baik di lingkungan tempat kerja maupun tempat tinggal/rumah (Pelling, 2002).

Seiring bertambahnya waktu, konselor saat ini banyak memanfaatkan media online dalam melakukan tugasnya misalnya dalam meng-upgrade informasi, pengetahuan, serta mencari sumber referensi dan berdiskusi. Bahkan untuk proses konseling saat ini banyak dilakukan dalam ruang tertutup dan menggunakan media teknologi yang sering disebut dengan elektronik konseling, sehingga proses konvensional dengan tatap muka sudah mulai banyak ditinggalkan (Gibson, 2011).

Suatu upaya untuk memberikan pengalaman dan membuat kondisi seseorang, kelompok atau masyarakat dalam berbagai macam tatanan dengan cara memberikan informasi, memberikan edukasi serta melakukan diskusi dengan tujuan dapat meningkatkan pengetahuan, sikap dan perilaku masyarakat tersebut bisa dilakukan dengan metode konseling. Hal tersebut bisa ditempuh dengan cara mengadakan pembinaan suasana, adanya advokasi, pemberdayaan masyarakat untuk mengembangkan kemampuan serta pengetahuan masyarakat baik individu maupun kelompok agar dapat melakukan upaya promotif dan preventif agar derajat kesehatan masyarakat bisa meningkat (Nurihsan, 2006).

Menurut hasil data studi pendahuluan oleh peneliti, analisis instrumen ungkap masalah (AUM) yang dibagikan kesejumlah orang (20) untuk program sosialisasi konseling online pada bulan Mei 2020 bersamaan dengan kegiatan Posyandu, didapatkan masalah tertinggi dikalangan ibu-ibu tersebut mencakup 3 aspek, yaitu: 1) masalah bidang kesehatan dan mata pencaharian/pekerjaan yang mencapai $50 \%$; 2) masalah kecemasan diri sendiri terutama dalam kondisi pandemi saat ini sekitar 35\%; 3) kesehatan 
jasmani sebesar 25\%. Pada lembar jawaban yang berisi tentang penjelasan mengenai keseluruhan aspek yang menjadi masalah terdapat sekitar $50 \%$ orang dalam survei tersebut menyebutkan bahwa membutuhkan pelayanan konseling. Tetapi pada bagian pertanyaan mengenai siapa yang akan memberikan konseling, justru sebagian besar mengatakan lebih nyaman dengan hanya sekedar menceritakan masalahanya ke media sosial atau teman. Pada formulir instrumen selanjutnya, tentang konseling online ada $70 \%$ responden dalam survei tersebut ternyata belum mengetahui dan terpapar aplikasi tersebut (Data Primer, 2020).

Penelitian sejenis lainnya dari Astuti EK (2014) yaitu tentang pengaruh pendidikan kesehatan menggunakan media audio visual terhadap PHBS terdapat hasil yang signifikan berpengaruh positif (Astuti, 2014).

Partisipasiaktifmasyarakat dan penerapan PHBS di dalam keluarga bisa terlaksana jika keluarga memahami dalam menerima informasi tentang PHBS yang dikampanyekan, sehingga dapat menerima dengan baik dan dapat mengiplementasikannya. Peranan yang dilakukan masyarakat dalam menerapkan PHBS tergantung pada kondisi kognitif dan afektifnya ("Kementerian Pendidikan dan Kebudayaan Republik Indonesia Kamus Online “, 2004).

Untuk menjawab dan mengatasi kekurangan atau kendala yang terjadi seperti permasalahan di atas, maka penulis melakukan konseling tentang PHBS sesuai dengan kebutuhan dan kondisi masyarakat umum mayoritas saat ini yaitu mempermudah dengan tanpa membatasi jarak ruang dan waktu. Oleh karena itu, peneliti telah melakukan penelitian dengan judul "Efektivitas Konseling Berbasis Media Sosial Terhadap Perilaku Hidup Bersih dan Sehat (PHBS) Masyarakat Wilayah RW 17 Desa Bojongsoang di Masa Pandemi COVID-19", dengan tujuan untuk mengetahui efektivitas konseling berbasis media sosial terhadap PHBS masyarakat wilayah RW 17 Desa Bojongsoang di masa pandemik COVID-19.

\section{METODOLOGI}

Metode penelitian kuantitatif ini menggunakan pendekatan analitik dengan rancangan penelitian quasy experiment dengan desain one group pre-test post-test. Populasi dalam penelitian ini adalah pengguna media sosial WhatsApp group "komunikasi RT 02" yang berjumlah 82 orang/kontak/pengguna.

Adapun Pengambilan sampel dilakukan dengan quota sampling melalui rumus Slovin dari seluruh populasi. Kemudian menyebarkan kuesioner online kepada sampel kepada jumlah sampel penelitian sebanayak 40 orang responden dari populasi (Sugiyono, 2012a).

Tahapan dalam mengumpulkan data dan informasi terdiri dari tiga tahapan yaitu: pre-test, perlakuan/proses konseling, dan posttest. Tahapan pertama pre-test yaitu diawali dengan mencari data kontak/grup media sosial yang digunakan oleh responden, dilanjutkan memberikan kuesioner online dengan zoho form total pertanyaan 33 tentang, pengetahuan, sikap dan perilaku PHBS di masa pandemi covid-19 sebelum memberikan konseling kepada responden (pre-test) secara serempak dan dibatasi waktu pengisiannya (selama 30 menit) serta langsung diawasi oleh peneliti secara daring melalui media zoom meeting setelah peneliti melakukan inform consent dan persetujuan tindakan dari para responden/konseli.

Tahapan kedua proses perlakuan berupa konseling atau pemberian eksperimen/intervensi dilakukan pada satu kelompok tersebut yaitu kelompok yang diberi perlakuan konseling dengan media sosial WhatsApp tentang PHBS di masa pandemik COVID-19. Pada minggu pertama, materi konseling yang diberikan berupa video yang berisikan informasi PHBS secara 
umum dengan durasi 8-10 menit sebanyak 1 kali. Pada minggu kedua, materi konseling tentang PHBS diberikan berupa hand out/power point berisi gambar dan informasi PHBS sebanyak 15 slide yang dibuat oleh konselor disebarkan ke WhatsApp group kelompok perlakuan dan juga disertai dengan video penjelasan dari konselor secara langsung tentang materi hand out tersebut. Pada minggu ketiga, setelah responden mengikuti materi konseling yang diberikan, responden diberikan kesempatan dalam waktu seminggu untuk mengajukan pertanyaan/berdiskusi seputar materi PHBS yang telah diberikan, langsung kepada konselor melalui grup media sosial WhatsApp tersebut. Pada proses diskusi tersebut respon dari anggota WhatsApp group cukup aktif.

Tahapan ketiga post-test memberikan kuesioner online meliputi pengetahuan, sikap, dan perilaku tentang PHBS sesudah pemberian konseling (post-test) dengan jumlah dan soal yang sama seperti pre-test dengan zoho form daring melalui Zoom meeting diberikan waktu 30 menit dan disaksikan langsung oleh peneliti. Diakhir sesi pengisian post-test para konseli/ subjek penelitian mendapatkan kompensasi penelitian berupa kuota internet langsung ke nomer ponsel karena sebagai pengganti waktu dan penggunaan kuota internet yang telah tersita selama proses konseling sampai pengambilan data terakhir dengan total waktu 4 minggu. Jarak antara pre-test dan post-test adalah 3 minggu.

Data kuesioner diolah dengan software pengolahan data dan dianalisis menggunakan $U j i$ Wilcoxon. Sebelum tahap analisis, data terlebih dahulu dilakukan kategorisasi data tingkat pengetahuan, sikap dan perilaku responden sebelum dan sesudah kegiatan konseling. Kategori tingkat pengetahuan, sikap dan perilaku tersebut berdasarkan nilai mean dan simpangan baku data tersebut.

Instrumen yang digunakan untuk mengetahui karakteristik klien/konseli dengan menggunakan kuesioner dengan skala likert, pengetahuan menggunakan SPGBK, sikap, dan perilaku klien/konseli. Pengolahan dan analisa data kuesioner menggunakan Uji Wilcoxon. Adapaun tahapannya yaitu mulai dari mengkategorisasikan hasil pengetahuan, sikap dan perilaku sebelum dan sesudah tindakan konseling. Selanjutnya kategorisasi tersebut dilihat berdasarkan nilai rata-rata dan simpangan bakunya.(Budiman, 2013).

\section{HASIL}

\section{Gambaran Tempat Penelitian}

Nama Desa/Kelurahan : Bojongsoang, dengan total Penduduk : 924 terdiri dari jumlah Laki-Laki : 497 jiwa dan jumlah Perempuan : 427 jiwa dengan total jumlah KK : 339. Selain itu RW 17 Desa Bojongsoang terdiri sekitar $635 \mathrm{KK}$, termasuk ke wilayah kerja Puskesmas Bojogsoang dengan menyediakan layanan laboratorium, apotek, poli gigi, konseling, KIA.

Dalam penelitian ini peneliti mengambil responden yaitu ibu-ibu di wilayah kerja Posyandu mekar Arum di RW 17 RT 02 yang melakukan kunjungan posyandu sebanyak 82 responden dan pengambilan sampel dilakukan dengan quota sampling melalui rumus Slovin. Kemudian menyebarkan kuesioner online kepada sampel kepada jumlah sampel penelitian sebanayak 40 orang responden dari populasi. Sampel tersebut masuk ke dalam WhatsApp group untuk diberikan informasi/konseling mengenai PHBS melalui media social WhatsApp di masa pandemic covid-19 ini.

Tabel 1. Distribusi Frekuensi Karakteristik Responden

\begin{tabular}{lcc}
\hline \multicolumn{1}{c}{ Variabel } & f & \% \\
\hline Umur & & \\
$<20$ tahun & 2 & 5,0 \\
$1-35$ tahun & 30 & 75,0
\end{tabular}




\begin{tabular}{lcc}
\hline \multicolumn{1}{c}{ Variabel } & f & \% \\
\hline$>35$ tahun & 8 & 20,0 \\
\hline $\begin{array}{l}\text { Paparan informasi } \\
\text { Pernah }\end{array}$ & 16 & 40,0 \\
$\begin{array}{l}\text { Tidak Pernah } \\
\text { Paritas }\end{array}$ & 24 & 60,0 \\
Primipara & & \\
Multipara & 11 & 27,5 \\
Pendidikan & 29 & 72,5 \\
>SMA & & \\
SSMA sederajat & 34 & 85,0 \\
Pekerjaan & 6 & 15,0 \\
Bekerja & & \\
Tidak Bekerja (IRT) & 13 & 32,5 \\
\hline
\end{tabular}

(Sumber: Data Primer, 2020)

Berdasarkan tabel 1 dapat diketahui dari 40 responden bahwa distribusi frekuensi karakteristik usia didapatkan sebagian besar reproduksi sehat yaitu 75\% rentang umur 20-35

Analisis Univariat

Tabel 2. Rata-Rata Pengetahuan Sebelum dan Sesudah Dikonseling Berbasis Media Sosial PHBS

\begin{tabular}{cccccc}
\hline Responden & Rata-rata & Minimal & Maksimal & $\begin{array}{c}\text { Standar } \\
\text { Deviasi }\end{array}$ & Frekuensi \\
\hline Pre-test & 70,38 & 55 & 83 & 5,578 & 40 \\
Post-test & 79,37 & 71 & 83 & 2,947 & 40 \\
\hline
\end{tabular}

(Sumber: Data Primer, 2020)

Berdasarkan tabel 2 hasil analisis data menunjukkan bahwa pre-test pengetahuan PHBS dengan paling tinggi 83 , nilai paling rendah 51, rata-rata skor 70,38 dan standar deviasi 5,578.

Tabel 3. Kategori Hasil dari Sikap dan Perilaku Hidup Bersih dan Sehat (PHBS) Sebelum dan Sesudah Diberikan Konseling Berbasis Media Sosial

\begin{tabular}{ccccc}
\hline PHBS & \multicolumn{2}{c}{ Pre-test } & \multicolumn{2}{c}{ Pos-test } \\
\cline { 2 - 5 } Konseli/responden & Frekuensi & Persentase & Frekuensi & Persentase \\
\hline Baik & 34 & 85,0 & 38 & 95,0 \\
Kurang & 6 & 15,0 & 2 & 5,0 \\
\hline Jumlah & $\mathbf{4 0}$ & $\mathbf{1 0 0}$ & $\mathbf{4 0}$ & $\mathbf{1 0 0}$ \\
\hline
\end{tabular}

(Sumber: Data Primer, 2020) 
Berdasarkan tabel 3 terjadi peningkatan pada saaat pre-test dan post-test, kategori baik pada saat pre-test hanya sebesar $85 \%$, tetapi setelah diberikan konseling menjadi 95\%. Hasil pre-test tersebut hanya sedikit perbedaannya dengan hasil post-test berdasarkan kuesioner penelitian, responden menyatakan bahwa para konseli/ masyarakat sudah mendapatkan penyuluhan dari Puskesmas setempat saat kegiatan Posyandu pada awal pandemk COVID-19 ada satu kali dan dari bidan desa tersebut diberikan lagi tentang menjaga pencegahan COVID -19 yang isi materinya merupakan bagian dari konten PHBS di tatanan rumah tangga sehingga ini mempengaruhi pengetahuan dan sikap responden karena sudah terpapar informasi tersebut sebelumnya.

\section{Uji Normalitas Data}

Menggunakan program Saphiro wilk test pada computer proses uji normalitas dilakukan. Menggunakan tingkat signifikasi 0,05, jika didapatkan nilai taraf signifikasi hitung lebih $>$ lebih besar dari nilai taraf dengan signifikasi 0,05 artinya data terdistribusi normal. Masingmasing variabel penelitian berdasarkan hasil uji normalitasnya, disajikan sebagai berikut:

Tabel 4. Nilai Uji Normalitas Data

\begin{tabular}{ccccc}
\hline Variabel & Statistik & Df & Signifikasi & Keterangan \\
\hline Pre-test Perilaku & 0,974 & 40 & 0,744 & Normal \\
Post-test Perilaku & 0,928 & 40 & 0,033 & Tidak normal \\
\hline
\end{tabular}

Berdasarkan tabel 4 didapatkan nilai signifikasi data pre-test 0,744 dan post-test nilai signifikasinya 0,033 . Berdasarkan nilai uji normalitas tersebut diketahui bahwa hanya nilai pre-test saja terdistribusi normal, sedangkan post-test terdistribusi tidak normal. Maka apabila setelah dilakukan uji normalitas data terdistribusi tidak normal analisis menggunakan uji statistic non parametric Wilxocon (Sugiyono, 2012b)

\section{Analisis Bivariat}

Tabel 5. Rata-rata Pengaruh Konseling berbasis Media Sosial Terhadap PHBS

\begin{tabular}{cccccc}
\hline Variabel & & N & Mean Ranks & Sun of Rank & Sign \\
\hline Pre-test & Negative Rank & $2^{\mathrm{a}}$ & 5,00 & 18,00 & 0,000 \\
Post-test & Positive Rank & $38^{\mathrm{b}}$ & 23,21 & 1007,00 & (signifikan) \\
& Ties & $0^{\mathrm{c}}$ & & & \\
\hline & Total & $\mathbf{4 0}$ & & \\
\hline
\end{tabular}

Keterangan:

$2^{\mathrm{a}}=$ perilaku post-test $<$ perilaku pre-test

$38^{\mathrm{b}}=$ perilaku post-test $>$ perilaku pre-test

$0^{c}=$ perilaku post-test $=$ perilaku pre-test

Melihat tabel 5 tersebut ada 38 responden yang mempunyai nilai post-test lebih naik lebih baik dari pada pre-test, responden mempunyai perilaku post-test kurang dari pre-test dan 0 responden yang mempunyai nilai post-test sama dengan pre-test. Nilai signifikasi kurang dari 0,selanjutnya ada pengaruh konseling berbasis media sosial terhadap pengetahuan, sikap dan perilaku hidup bersih dan sehat pada masyarakat RW 17 Desa Bojongsoang di masa pandemik COVID -19. 


\section{PEMBAHASAN}

\section{Tingkat Pengetahuan Responden Sebelum dan Sesudah Pemberian Informasi Tentang PHBS berbasis Media Media Sosial.}

Berdasarkan hasil penelitian didapatkan jumlah responden dengan usiareproduksi tidak sehat $(<20$ dan $>35$ tahun) yaitu $25 \%$ dan usia reproduksi sehat $(20-35$ tahun) yaitu $75 \%$. Ratarata umur warga adalah mereka yang masih dalam usia produktif yaitu 26-35 tahun. Hal ini sesuai dengan penelitian yang dilakukan oleh Putra (2017), bahwa pada usia produktif merupakan usia yang paling berperan dan memiliki aktivitas yang padat serta memiliki kemampuan kognitif yang baik. Sehingga, pada usia ini memiliki pengaruh terhadap tingkat pengetahuan. Hal ini juga yang mendasari pembagian umur tersebut berdasarkan faktor risiko yang dialami seorang wanita (Putra Agina Widyaswara Suwaryo, 2017).

Menurut Budiman dan Riyanto (2013), faktor yang mempengaruhi pengetahuan meliputi pendidikan, informasi/media massa, sosial, budaya dan ekonomi, lingkungan, pengalaman dan usia (Budiman, 2013).

Hasil penelitian pada latar belakang pendidikan terakhir responden adalah 15\% dengan pendidikan rendah ( $\leq$ SMA sederajat), $85 \%$ dengan pendidikan tinggi ( $>$ SMA). Menurut Budiman dan Riyanto (2013), semakin tinggi pendidikan seseorang maka semakin cepat menerima dan memahami suatu informasi sehingga pengetahuan yang dimiliki juga semakin tinggi. Hal ini sejalan dengan penelitian yang dilakukan oleh Applonia dkk tentang faktor-faktor yang mempengaruhi perilaku pemeliharaan kebersihan gigi dan mulut ibu hamil di Puskesmas Kabupaten Kupang yang menjelaskan bahwa pengetahuan berpengaruh secara signifikan terhadap perilaku pemeliharaan kesehatan gigi dan mulut selama masa kehamilan, dimana pengetahuan tersebut dipengaruhi oleh pendidikan seseorang sehingga semakin tinggi pendidikan seseorang maka semakin baik pula pengetahuannya (Applonia Applonia, 2014).

Berdasarkan pekerjaan yang dimiliki oleh responden didapatkan responden yang tidak bekerja atau sebagai ibu rumah tangga sebesar $67,5 \%$ dan responden yang memiliki pekerjaan sebesar 32,5\%. Menurut penelitian Risti Afiati dkk yang berjudul hubungan perilaku ibu tentang pemeliharaan kesehatan gigi dan mulut terhadap status karies gigi anak menjelaskan bahwa status sosial atau pekerjaan mempengaruhi perilaku hidup sehat pada seseorang. Orang dengan status sosial yang rendah cenderung mengabaikan perilaku hidup sehat sedangkan pada kelompok sosial tinggi akan lebih besar minat hidup sehatnya (Risti Afiati, 2017).

Hasil penelitian berdasarkan sumber informasi tentang PHBS pada responden sebesar $60 \%$ responden belum pernah mendapatkan informasi sebelumnya dan yang sudah pernah mendapatkan informasi tentang PHBS yaitu $40 \%$. Tetapi meskipun sebelumnya sudah mendapatkan informasi tentang kesehatan/PHBS, Sebagian besar responden yang mengatakan bahwa belum mengetahui informasi tentang PHBS secara keseluruhan utamanya ditatanan rumah tangga di masa pandemik COVID-19 seperti saat ini. Menurut Budiman dan Riyanto (2013), informasi memengaruhi pengetahuan seseorang jika sering mendapatkan informasi tentang suatu pembelajaran maka akan menambah pengetahuan dan wawasannya, sedangkan seseorang yang tidak sering menerima informasi tidak akan menambah pengetahuan dan wawasannya.

Hal ini sesuai dengan teori yang dilakukan oleh Christian Rompis dkk dan penelitian tentang pengaruh penggunaan media sosial Facebook dan dukungan sosial online terhadap perilaku pemberian ASI, yang menjelaskan bahwa penggunaan Facebook efektif dan berpengaruh terhadap perilaku responden (Yasya, Muljono, 
Seminar, \& Hardinsyah, 2019).

Rata-rata pengetahuan responden tentang PHBS sebelum diberikan pendidikan kesehatan dengan media sosial WhatsApp sebesar 70,38 maka dapat disimpulkan bahwa sebagian besar responden belum mengetahui secara lengkap informasi tentang PHBS dikarenakan masih kurangnya informasi yang didapat oleh responden yaitu sebesar $40 \%$ responden belum pernah mendapatkan informasi tentang PHBS di tatanan rumah tangga di masa pandemik COVID-19. Responden perlu mengetahui informasi tentang PHBS di masa pandemik karena mengerti manfaat mempraktekkan hidup bersih dan sehat maka dapat mencegah berbagai macam penyakit utamanya dalam situasi/kondisi pandemi COVID-19 seperti saat ini.

Berdasarkan hasil penelitian setelah post-test, rata-rata pengetahuan tentang PHBS responden/konseli yang hampir sebagian besar ibu rumah tangga, meningkat menjadi 79,37, maka dapat disimpulkan bahwa terdapat peningkatan rata-rata pengetahuan responden setelah mendapat informasi tentang PHBS dimasa pandemi COVID-19 ini. Hal ini membuktikan bahwa pemberian informasi berupa konseling dan penkes dengan sasaran ibu rumah tangga dapat meningkatkan pengetahuan seperti pada hasil penelitian sebelumnya menurut Aswadi, dkk (2020) yang menyatakan bahwa kegiatan pemberdayaan masyarakat yang dilakukan oleh pihak puskesmas berupa konseling, posyandu, pelatihan bagi kader, serta penyuluhan PHBS tatanan rumah tangga dengan ibu rumah tangga sebagai sasaran utama (Aswadi, M, \& S, 2020).

Berdasarkan hasil Uji Wilcoxon didapatkan hasil p-value 0,000 maka dapat disimpulkan bahwa terdapat efektivitas yang berpengaruh dari konseling melalui media sosial WhatsApp terhadap peningkatan pengetahuan, sikap dan perilaku hidup bersih dan sehat (PHBS) pada masyarakat Desa Bojongsoang di mas pandemic COVID-19 saat ini. Sesuai dengan penelitian yang dilakukan oleh Muhammad Syarif Buang dkk tentang efektivitas pendidikan kesehatan dengan audio visual terhadap pengetahuan dan perilaku hidup sehat tentang pencegahan penularan tuberkulosisi paru yang menjelaskan bahwa terdapat perbedaan skor pengetahuan berdasarkan hasil analisa statistic dengan uji $\mathrm{t}$ dependent diperoleh p-value $0,000<\alpha(0,05)$ yang berarti ada perbedaan yang bermakna pengetahuan keluarga sesudah diberikan pendidikan kesehatan dengan audiovisual (Persada UNICEF, March 2020).

Adanya perbedaan nilai pre-test dan post-test membuktikan bahwa penggunaan media audiovisual efektif digunakan untuk meningkatkan pengetahuan. Berdasarkan penelitian yang telah dilakukan didapatkan hasil yaitu $P$-value 0,000 sehingga dapat disimpulkan bahwa terdapat perbedaan peningkatan pengetahuan tentang PHBS sebelum dan sesudah diberikan konseling melalui media sosial WhatsApp karena konten/materi konseling yang disampaikan kepad konseli mengandung unsur audiovisual.

Hal ini didukung juga dengan penelitian yang dilakukan oleh Agni Rimba Mawan tentang PHBS dalam menanggulangi diare pada masyarakat, didapatkan bahwa terjadi peningkatan nilai rata-rata setelah menggunakan video penyuluhan yang signifikan. Media audiovisual memiliki dua unsur yaitu suara dan gambar, sehingga keahliannya lebih baik saat digunakan (Agni Rimba Mawan, 2017).

Hal ini sesuai dengan pengertian pendidikan kesehatan atau promosi kesehatan berdasarkan kutipan Piagam Ottawa (Ottawa Charter, 1986). Piagam tersebut menyatakan bahwa Pendidikan kesehatan sebagai langkah promosi kesehatan adalah suatu proses untuk memberdayakan masyarakat dalam memelihara dan meningkatkan status kesehatan masyarakat 
(Promotion, 1986).

Pada penelitian ini terjadi peningkatan yang signifikan antara pengetahuan sebelum dan sesudah pemberian media sosial WhatsApp tentang PHBS pada masyarakat/ibu-ibu diwilayah Desa Bojongsoang di masa pandemi COVID -19. Hal ini memperkuat bahwa media sosial merupakan media konseling/ promosi kesehatan yang efektif dan bermanaat bagi para responden dalam meningkatkan pengetahuan tentang PHBS di tatanan rumah tangga. Media merupakan salah satu hal yang perlu diperhatikan dalam melakukan promosi kesehatan. Penggunaan media dalam pendidikan kesehatan memiliki berbagai fungsi seperti: mengatasi keterbatasan ruang, waktu serta bahasa dan panca indera, mengarahkan peminatan, menangani sikap tidak aktif pada respondenmanfaat seperti merangsang minat sasaran, mengatasi keterbatasan ruang, waktu, bahasa, dan daya indera pada proses penerimaan pendidikan, mengatasi sikap pasif sasaran, memberikan rangsangan, pengalaman serta menimbulkan persepsi yang sama. Hal ini mendorong keinginan sasaran untuk lebih mengetahui, mendalami, serta memahaminya yang akhirnya memberikan pengertian yang positif mengenai pesan kesehatan yang dimaksud. Selanjutnya sasaran akan meneruskan pesan tersebut kepada orang lain sehingga sasaran yang diperoleh lebih banyak.

\section{SIMPULAN DAN SARAN}

Berdasarkan hasil penelitian dan pembahasan, mada penelitian ini dapat diambil kesimpulan sebagai berikut: 1) Terdapat peningkatan pengetahuan antara hasil pre-test dan post-test pada sebelum dan sesudah diberikan perlakuan dengan media sosial WhatsApp hasil p-value 0,000 maka dapat disimpulkan terdapat efektivitas yang berpengaruh dari konseling melalui media sosial WhatsApp terhadap peningkatan pengetahuan, sikap dan perilaku hidup bersih dan sehat (PHBS) 2) Terdapat pengaruh pemberian konseling berbasis media sosial terhadap peningkatan pengetahuan, sikap dan perilaku hidup bersih dan sehat pada masyarakat wilayah RW 17 Desa Bojongsoang di Masa Pandemi COVID -19. 3) Tidak ada pengaruh karakteristik responden terhadap peningkatan pengetahuan tentang PHBS pada masyarakat RW 17 desa Bojongsoang di Masa Pandemi COVID -19. 4) Penggunaan media sosial WhatsApp dalam konseling mengenai PHBS efektif meningkatkan pengetahuan responden. Bagi peneliti selanjutnya diharapkan dapat mengembangkan penelitian ini dengan menambahkan variable perilaku dan kelompok pembanding

\section{DAFTAR PUSTAKA}

Agni Rimba Mawan, S. E. I., Suhadi Suhadi. (2017). Pengembangan Video Penyuluhan Perilaku Hidup Bersih Dan Sehat (Phbs) Bermuatan Nilai Karakter Terhadap Peningkatan Pengetahuan Masyarakat Dalam Menanggulangi Penyakit Diare. Jurnal Pendidikan: Teori, Penelitian, \& Pengembangan Journal Of Education Graduate School Of Universitas Negeri Malang, 2, No.7, 883-888. Retrieved from http://journal.um.ac.id/index.php/ jptpp/article/view/9606

Applonia Applonia, B. P., Niken Widyanti.(2014). Faktor-faktor yang Mempengaruhi Perilaku Pemeliharaan Kebersihan gigi dan Mulut Ibu Hamil di Puskesmas Kabupaten Kupang. Majalah Kedokteran Gigi Indoensia. Vol 21, No 1

Astuti, E. K. (2014). Pengaruh Pendidikan Kesehatan Dengan Media Audio Visual Terhadap Perilaku Hidup Bersih dan Sehat (PHBS) Pada Siswa Kelas III-V Di SD Negeri Purworejo. (Skripsi). Universitas Aisyiyah Yogyakarta, 
Aswadi, M, S., \& S, S. (2020). Strategi Promosi Kesehatan dalam Peningkatan Program Perilaku Hidup Bersih dan Sehat Tatanan Rumah Tangga di Puskesmas Polombangkeng Selatan Kabupaten Takalar. Higiene, 6 no.1.

Budiman, R. A. (2013). Kapita Selekta Kuisioner Pengetahuan Dan Sikap Dalam Penelitian Kesehatan. Jakarta: Salemba Medika.

Gibson, R. L., \& Mitchell, M.H. (2011). Bimbingan dan Konseling. (Terjemahan Yudi Santoso) (B. a. d. t. 2008 Ed.). Yogyakarta:: Pustaka Pelajar.

Ifdil. (2013). Elektronik konseling sebagai salah satu bentuk pelayanan e-konseling [Versi elektronik]. Jurnal Konseling dan Pendidikan, 1, 15-21.

- Kementerian Pendidikan dan Kebudayaan Republik Indonesia Kamus Online (2004). Retrieved from KBBI.http://kbbi. web.id/elektronik

Nurihsan, A. J. (2006). Bimbingan dan Konseling dalam Berbagai Latar Belakang. Bandung: PT. Refisika Aditama.

Pelling, N. (2002). The Use Technology in Career Counseling. . Journal of Technology In Counseling, Vol. 2-2.

Persada UNICEF. (March 2020.). Key Messages and Actions for COVID-19 Prevention and Control in Schools Retrieved from https:// www.unicef.org/romania/documents/ key-messages-and-actionsCOVID-19prevention-and-control-schools
Promotion, O. C. f. H. (1986). Available From: www.who.int/hpr/NPH/docs/ ottawa charter_hp.pdf February 2010. diakses tanggal 24 Juli 2014

Putra Agina Widyaswara Suwaryo, P. Y. (2017). Faktor-Faktor Yang Mempengaruhi Tingkat Pengetahuan Masyarakat dalam Mitigasi Bencana Alam Tanah Longsor. The 6th University Research Colloquium 2017 Universitas Muhammadiyah Magelang.

Risti Afiati, R. A., Karina Ramadhani, Sherli Diana. (2017). Hubungan Perilaku Ibu Tentang Pemeliharaan Kesehatan Gigi Dan Mulut Terhadap Status Karies Gigi Anak Tinjauan Berdasarkan Pengetahuan, Tingkat Pendidikan, Dan Status Sosial. Jurnal Kedokteran Gigi, 2, No 1. Retrieved from https://ppjp.ulm. ac.id/journal/index.php/dentino/article/ view/2601

Sugiyono.(2012a). Metode Penelitian kuantitatif, kualitatif, dan $R \&$ D. Bandung: Alfabeta. Sugiyono.(2012b). Metode Penelitian kuantitatif, kualitatif, dan $R \& D$. . Bandung:: Alfabeta.

Yasya, W., Muljono, P., Seminar, K. B., \& Hardinsyah. (2019). Pengaruh Penggunaan Media Sosial Facebook dan Dukungan Sosial Online Terhadap Perilaku Pemberian Asi. Jurnal Studi Komunikasi Dan Media, vol. 23 no.1, 7186. 